\title{
Anti-inflammatory Property of the Formulated Topical Gel from the Crude Leaf Extracts of Sampaguita (Jasminum sambac L. Family: Oleaceae)
}

\author{
Yvonne Mae C. Belango, Arlene F. Cruz, Rhoda B. Miguel, Chad Rilyn L. Rotairo, and Riel Anthony \\ T. Oli
}

\begin{abstract}
Sampaguita (Jasminum sambac L.) crude leaf extracts had been known to possess anti-inflammatory properties. The study was conducted to determine the antiinflammatory property of the formulated topical gel from the extract of Sampaguita, Jasminum sambac Linn. (Family: Oleaceae) against $1 \%$ diclofenac emugel as positive control.

The leaves of Sampaguita were collected in San Pedro, Laguna, Philippines. The collected leaves were subjected to Soxhlet apparatus with $80 \%$ methanol as solvent. The extract was concentrated with the use of Rotary evaporator and was lyophilized. The extract obtained was used for the formulation of the different concentration of topical gel. Color, homogenicity, consistency, phase separation, $\mathrm{pH}$, and viscosity were performed to characterize the formulated gel.

Carageenan-induced paw edema was used as the method in the evaluation of anti-inflammatory activity of the different concentrations of the formulated gel. The phlogistic agent, carrageenan, was used to induce the inflammation on the right hind paw of Sprague-Dawley rats. The foot volume measurement was obtained with the used pletysmometer as the mean of inflammatory measurement. Evaluating the different gel formulation if it is tolerable patch and scratch was carried out.
\end{abstract}

Lastly, based on the three trials done on the antiinflammatory activity evaluation using One-Way Analysis of Variance (ANOVA) and a follow-up Tukey test, the Jasminum sambac Linn. leaves' extract retained its anti-inflammatory property in the formulated topical gel and have proven their worth as an anti-inflammatory agent.

Index Terms-Anti-inflammatory, pletysmometer, Sampaguita, Soxhlet apparatus.

\section{INTRODUCTION}

Inflammation is a reaction to tissue injury caused by the release of chemical mediators that cause both a vascular response and the migration of fluid and leukocytes or white blood cells at the injured tissue or infection site. The causes of inflammation include trauma, surgical interventions, extreme heat or cold, infection by pathogens, and immune reactions due to hypersensitivity. Inflammatory response is a protective mechanism in which the body attempts to neutralize and destroy harmful agents at the site of injury and to establish conditions for tissue repair via release of chemical mediators such as prostaglandins. Redness, heat,

Manuscript received April 21, 2015; revised June 30, 2015.

Yvonne Mae C. Belango, Arlene F. Cruz, Rhoda B. Miguel, and Chad Rilyn L. Rotairo are with Adamson University, Ermita, Manila, Philippines.

Riel Anthony T. Oli is with Adamson University, Ermita, Manila, Philippines. He is also with the the University of Santo Tomas, España, Manila, Philippines (e-mail: rielanthonyoli@gmail.com). swelling, pain, and loss of function are the five responses to tissue injury and are also called the cardinal signs of inflammation [1]. Though these signs and symptoms are necessary for tissue repair, it can be noxious to people thus must be treated. Inflammation can be treated with drugs known as anti-inflammatory agents.

As a result of searching for a more effective drug with fewer side effects, many other anti-inflammatory agents, or prostaglandin inhibitors, have been discovered which may include those obtained from plants. Plants have played an important role in the traditional medicine from the earliest times. Medicinal plants and the albularyo (herbolario) are part of Filipino cultural heritage. These plant products have been used in the treatment of diseases for many years and could be considered to be the first remedy for pain and inflammation [2].

Several tests on adult male Wistar albino rats and albino mice using Petroleum ether extracts of $J$. sambac L. were conducted. Tests on its anti-inflammatory properties included writhing test, tail immersion test, hot plate method, and carrageenan-induced edema. Petroleum ether extracts of J. sambac Linn. leaves have exhibited anti-inflammatory property which could account for its effectiveness for acute inflammatory disorders [3]. However, crude extracts cannot easily be administered to living organisms due to the dose, which may be too small, or may cause irritation if applied as it is.

Formulation of a dosage form is necessary to easily administer the leaf extracts of $J$. sambac. Topical preparations such as creams, ointments, and gels may be prepared wherein it can be spread to local inflammation sites which are commonly experienced by patients like those with arthritis. Preparation for anti-inflammatory agents available in the market utilized gels. Gels, as per definition of the United States Pharmacopeia (USP), are semisolid system consisting of dispersion made up of either small inorganic particle or large organic molecule enclosing and interpenetrated by liquid. Most topical gels are prepared with organic polymer, such as carbomers, base which contains large amounts of oleaginous substances that provides moisturizing and emollient effects to dry irritated skin due to the occlusion of moisture from the skin to the environment. The moisturizing effect allows the dissolution of the drug, which is otherwise dispersed as fine particles in the ointment base, in the moisture layer. Since only the dissolved drug presented to the skins, as an individual molecular entity is able to enter the stratum corneum layer of the skin, the occlusion generally results in enhanced 
percutaneous drug absorption [4].

This study aims to provide and contribute towards the improvement of man's health. Also, the study aims for the acceptance of J. sambac Linn. leaves as a constituent of an anti-inflammatory agent such as gels. This study will be a great step towards discovering the extent of application of its curative properties.

\section{RESEARCH Methodology}

The study employed an experimental, randomized block design. The study was conducted in the Pharmacy laboratories of Adamson University, Manila, Philippines

The study utilized collection of fresh mature leaves of $J$. sambac from San Pedro, Laguna. The leaves were thoroughly cleaned, washed with clean water, garbled, and comminuted.

\section{A. Preparation of Plant Extract}

The comminuted leaves were weighed and transferred into a thimble. Cotton mass was placed on top of the sample and extracted using a Soxhlet apparatus with $80 \%$ methanol as solvent. After eight hours, the crude extract was concentrated using a rotatory evaporator and was subjected to lyophilization. The lyophilized dry powder was used in the preparation of the topical gel.

\section{B. Preparation of Topical Gel}

TABLE I: J. SAMBAC EXTRACT GEL FORMULATION FOR $60 \mathrm{ML}$

\begin{tabular}{|l|l|}
\hline Ethanol & $29.5 \mathrm{~mL}$ \\
\hline Carbomer & $0.23 \mathrm{~g}$ \\
\hline Propylene glycol & $5.5 \mathrm{~mL}$ \\
\hline Distilled water & $23.6 \mathrm{~mL}$ \\
\hline Triethanolamine & q.s. \\
\hline Sodium metabisulfite & $0.6 \mathrm{~g}$ \\
\hline
\end{tabular}

The study utilized the emugel formulation by Shivhare, et al. (2012) to determine the amount of active substance to be used which is one gram for a $60 \mathrm{~mL}$ preparation. The working formula was derived from the gel-based alcohol formulation of Adamson University Manufacturing Pharmacy Manual [5], [6]. Table I shows the different content and the concentration of each component of the formulated gel used in the study

Using ratio and proportion, the researchers derived different concentrations of J. sambac Linn. topical gel. Formulations were summarized in Table II.

TABLE II: WEIGHT OF J. SAMBAC LINN. POWDER FOR THE DIFFERENT CONCENTRATION OF SAMPAGUITA TOPICAL GEL FOR $60 \mathrm{ML}$

\begin{tabular}{|c|c|c|c|c|c|}
\hline Ingredients & $\begin{array}{c}\text { Negative } \\
\text { Control }\end{array}$ & $0.25 \%$ & $0.50 \%$ & $0.75 \%$ & $1.0 \%$ \\
\hline $\begin{array}{c}\text { J. sambac Linn. } \\
\text { powder (g) }\end{array}$ & - & $0.15 \mathrm{~g}$ & $0.30 \mathrm{~g}$ & $0.45 \mathrm{~g}$ & $0.60 \mathrm{~g}$ \\
\hline
\end{tabular}

Carbomer and sodium metabisulfite were weighed and all the liquid ingredients were measured. The carbomer was dispersed in $23.6 \mathrm{~mL}$ of distilled water containing 0.6 grams of sodium metabisulfite as antioxidant. The solution was then heated at $75^{\circ} \mathrm{C}$ using a water bath to allow the entrapped air to escape. To this solution, $5.5 \mathrm{~mL}$ of propylene glycol was added and mixed for five (5) minutes (Solution A).

Specific amounts of Jasminum sambac Linn. powdered extract was weighed and stirred to dissolve in ethyl alcohol (Solution B).

Solutions A and B were mixed thoroughly and drops of triethanolamine was added until the desired consistency was achieved. The solution was subjected in the homogenizer for 10 minutes smooth texture of the gel.

Each of the prepared topical gels with $0.25 \%, 0.50 \%$, $0.75 \%$, and $1.0 \%$ concentrations were filled in a collapsible tin tube and stored in a cool dry place.

The concentrations were derived to have an equal percent difference on the each of the concentrations. As the concentration increases a $0.25 \%$ is added to compare to other concentrations if the addition of $0.25 \%$ will have a greater anti-inflammatory effect.

\section{Evaluation of the Formulated Topical Gel}

The above formulated topical gels containing J. sambac Linn. leaves' extract were subjected for evaluation using the following parameters:

\section{1) Physical Appearance}

The prepared gel formulations were inspected visually for their color, homogeneity, consistency, and phase separation.

\section{2) Measurement of $\mathrm{pH}$}

The $\mathrm{pH}$ of different gel formulations was obtained using digital $\mathrm{pH}$ meter. One gram of gel was dissolved in $100 \mathrm{~mL}$ of distilled water and the $\mathrm{pH}$ was measured. The measurement of $\mathrm{pH}$ of each formulation was done in triplicate and average values were calculated [7].

\section{3) Measurement of the viscosity}

The viscosity of the formulated batches was determined using a Brookfield Viscometer with a cylindrical spindle no. 7. The formulation whose viscosity was to be determined was placed in the beaker and was allowed to settle down for 30 minutes at the assay temperature of $25+/-1^{\circ} \mathrm{C}$. Before the measurement was taken the spindle was lowered down perpendicular to the center of the gel while assuring that the spindle would not touch the bottom of the beaker and it was rotated at a speed of $1.5 \mathrm{rpm}$ for 10 minutes. The corresponding viscosity reading was noted. The average of the three readings was taken in 10 minutes and was noted as the viscosity of the gel [8], [9].

\section{4) Animal testing (sensitivity testing)}

Patch and Scratch tests based from Guevara, B. et al. (2005) were used to determine the safety of the topical application of the gel containing a certain amount of Jasminum sambac Linn. leaves' extract. The skin irritation studies were also carried out to evaluate the tolerability of the gel components after application to the skin.

\section{a) Patch test}

A group of four male guinea pigs were selected. The skin lateral to the spinal groove of the guinea pigs are cleaned with $70 \%$ isopropyl alcohol and then shaved. The left side of the groove of the animals were utilized as the negative control site and the right side as the test drug site. Both sides $(1 \times 1$ inch) are treated with appropriate amount of the test drug and covered with gauze secured with surgical tape to 
keep it in place. The guinea pigs were left undisturbed for 24 to 72 hours while under the treatment. The test animal's skin reaction was evaluated according to erythema and edema formation after 24 and 72 hours period of exposure. The average scores of the 24 and 72 hours reading were noted and computed using the formula:

$$
\begin{aligned}
& \text { After } 24 \text { and } 72 \text { - hours reading : } \\
& =\frac{\text { Total Score }}{\text { Total score for Erythema }}
\end{aligned}
$$

\section{b) Scratch test}

A group of four male guinea pigs were also selected. The skin lateral to the spinal groove of the guinea pigs were shaved, cleaned with $70 \%$ isopropyl alcohol, and abraded by slightly scratching the skin of the test animals five to seven times with a 20 gauge hypodermic needle. The test drug was applied immediately on the abraded skin. The left sides of the groove of the animals were utilized as the negative control site and the right side as the test drug site. The guinea pigs are left undisturbed for 24 to 72 hours while under the treatment. The test animal's skin reaction was evaluated according to erythema and edema formation after 24 and 72 hours period of exposure. The average scores of the 24 and 72 hours reading were noted and computed. The averages of the scores for the patch and scratch tests were combined and the primary irritation index was computed using the formula:

\section{Primary Irritation Index \\ $=(1 / 2)$ (Ave. of the Patch and Scratch Test)}

The result was evaluated using the irritating rating from Federal Hazardous Substances Act Dermal Classification System [10], [11].

\section{Carageenan-Induced Edema Test for Anti- inflammatory Properties}

The protocol followed was described by Kulkarni, et al. (2010). The test animals weighing 150 to 200 grams were fasted for 24 hours before the experiment with free access to water only. Approximately $0.1 \mathrm{~mL}$ of $1 \%$ carageenan solution was injected into the plantar side of the right hind paw of the rats. Paw volume was measured and noted immediately after the carrageenan injection. Afterwards, $10 \mathrm{mg} / \mathrm{g}$ of the formulated topical gel with $0.25 \%, 0.50 \%$, $0.75 \%$ and $1.0 \%$ were applied to the plantar surface of the right hind paw. The gel was gently rubbed 50 times with the use of index finger. As for the standard, test animals of the control groups also received the plain gel base and $10 \mathrm{~g} / \mathrm{g}$ of $1.0 \%$ diclofenac sodium gel and applied in the same way as the other groups. Paw volume was measured at one hour interval for maximum of four hours after the administration of carrageenan solution using a plethysmograph.

The measurement of the test animal's foot volume for each formulation was done in three trials and values were calculated.

\section{E. Data Analysis}

The data collected from the readings of plethysmograph was tabulated. The data were subjected to statistical evaluation using one-way Analysis of Variance (ANOVA) to determine if there were significant differences on the recorded plethysmograph' readings that denotes antiinflammatory findings. A follow-up Tukey test was performed to determine where the significant differences lie and if there are significant differences among the values. The study set an alpha level of significance at 0.05 [12].

\section{RESULTS AND CONCLUSION}

Nine soxhlet apparatuses were used simultaneously to obtain the methanolic extract which was later concentrated and lyophilized. A total of $29.9590 \mathrm{~g}$ of J. sambac Linn. powder was obtained from $360 \mathrm{~g}$ of fresh leaves. The percent yield is $6.93 \%$.

All formulation batches were found to be yellow green to green translucent viscous preparations with a smooth homogenous texture, while the positive emugel was found to be white milky cream preparation.

TABLE III: PHYSICOCHEMICAL CHARACTERISTICS OF THE DIFFERENT GEL

\begin{tabular}{|c|c|c|c|c|}
\hline Formulations & Color & Homogeneity & Consistency & $\begin{array}{c}\text { Phase } \\
\text { Separation }\end{array}$ \\
\hline $\begin{array}{c}\text { Negative } \\
\text { control }\end{array}$ & $\begin{array}{c}\text { Clear, } \\
\text { transparent }\end{array}$ & Good & ++ & None \\
\hline $\begin{array}{c}\text { Positive } \\
\text { control }\end{array}$ & White & Good & +++ & None \\
\hline $0.25 \%$ & $\begin{array}{c}\text { Light } \\
\text { yellow } \\
\text { green } \\
\text { transparent } \\
\text { Yellow } \\
\text { green } \\
\text { transparent }\end{array}$ & Good & ++ & None \\
\hline $0.50 \%$ & $\begin{array}{c}\text { Light green } \\
\text { transparent }\end{array}$ & Good & ++ & None \\
\hline $0.75 \%$ & $\begin{array}{c}\text { Green } \\
\text { transparent }\end{array}$ & Good & ++ & None \\
\hline $1.0 \%$ & \multicolumn{1}{|c|}{} & ++ & None \\
\hline
\end{tabular}

Table III shows the results of the physical characterization of the formulated gel. The $\mathrm{pH}$ of the gel formulations was in the range of 6.35 to 7.65 , which is slightly above the normal $\mathrm{pH}$ range of the adult skin (5.5). The $\mathrm{pH}$ obtained from the different preparations is still considered acceptable by Braun-Falco (1986) to avoid the risk of irritation upon application to the skin [13].

TABLE IV: VISCOSITIES OF DIFFERENT GEL FORMULATIONS

\begin{tabular}{|c|c|c|c|c|}
\hline Formulations & $1^{\text {st }}$ reading & $2^{\text {nd }}$ reading & 3rd reading & $\begin{array}{c}\text { average } \\
\mathrm{mPa} \text { s }\end{array}$ \\
\hline $\begin{array}{c}\text { Negative } \\
\text { control }\end{array}$ & $1,138.0$ & $1,134.0$ & $1,131.1$ & $1,134.4$ \\
\hline Positive control & 916.0 & 956.0 & 942.8 & 938.3 \\
\hline $0.25 \%$ & $1,128.2$ & $1,126.0$ & 1124.0 & $1,126.1$ \\
\hline $0.50 \%$ & $1,116.6$ & $1,112.4$ & $1,108.2$ & $1,112.4$ \\
\hline $0.75 \%$ & $1,114.0$ & $1,112.0$ & $1,110.2$ & $1,112.1$ \\
\hline $1.0 \%$ & $1,110.0$ & $1,108.3$ & $1,105.0$ & $1,107.8$ \\
\hline
\end{tabular}

The viscosity of the formulated gels is higher than the positive control which is an emugel but is still comparable to the flow of the positive control as shown in Table IV.

Primary irritation index $=(1 / 2)($ Ave of the Patch and scratch test $)$

$=(1 / 2)(0+0.25)$

$=0.125$ (Non-irritant) 
TABLE V: SCORES FROM PATCH TEST

\begin{tabular}{|c|c|c|c|c|c|}
\hline \multirow{2}{*}{ Concentrations } & \multirow{2}{*}{$\begin{array}{c}\text { Guinea Pig } \\
\#\end{array}$} & \multicolumn{2}{|c|}{$\begin{array}{c}\text { Erythema } \\
\text { Score }\end{array}$} & \multicolumn{2}{c|}{$\begin{array}{c}\text { Edema } \\
\text { Score }\end{array}$} \\
\cline { 3 - 6 } & $24 \mathrm{hr}$ & $72 \mathrm{hr}$ & $24 \mathrm{hr}$ & $72 \mathrm{hr}$ \\
\hline $0.25 \%$ & 1 & 0 & 0 & 0 & 0 \\
\hline $0.50 \%$ & 2 & 0 & 0 & 0 & 0 \\
\hline $0.75 \%$ & 3 & 0 & 0 & 0 & 0 \\
\hline $1.0 \%$ & 4 & 0 & 0 & 0 & 0 \\
\hline & Average: & 0 & 0 & 0 & 0 \\
\hline
\end{tabular}

TABLE VI: SCORES FROM SCRATCH TEST

\begin{tabular}{|c|c|c|c|c|c|}
\hline \multirow[b]{2}{*}{ Concentrations } & \multirow[b]{2}{*}{$\begin{array}{c}\text { Guinea Pig } \\
\#\end{array}$} & \multicolumn{2}{|c|}{$\begin{array}{l}\text { Erythema } \\
\text { Score }\end{array}$} & \multicolumn{2}{|c|}{$\begin{array}{l}\text { Edema } \\
\text { Score }\end{array}$} \\
\hline & & $24 \mathrm{hr}$ & $\begin{array}{l}72 \\
\mathrm{hr}\end{array}$ & $24 \mathrm{hr}$ & $72 \mathrm{hr}$ \\
\hline $0.25 \%$ & 1 & 1 & 0 & 0 & 0 \\
\hline $0.50 \%$ & 2 & 1 & 0 & 0 & 0 \\
\hline $0.75 \%$ & 3 & 1 & 0 & 0 & 0 \\
\hline $1.0 \%$ & 4 & 1 & 0 & 0 & 0 \\
\hline & Average: & 1 & 0 & 0 & 0 \\
\hline
\end{tabular}

After 24-hours and 72-hours of treatment, all concentrations showed negative results for erythema and edema. The average results of the Patch and Scratch Test, shown in Table V and Table VI were computed using the Evaluation of Skin Reaction table shown on methodology. Using the computed average, the Primary Irritation Index was computed and the result was 0.125. Based on the Federal Hazardous Substance Act Dermal Classification System, the result indicated that the formulations were nonirritating.

It was observed that the gels were very well tolerated by the guinea pigs and no signs of erythema and/or edema were seen on the 24-hour and 72-hour intervals.

TABLE VII: AVERAGE READING OF THE FOOT EDEMA

\begin{tabular}{|c|c|c|c|c|c|c|}
\hline & $\begin{array}{c}\text { Before } \\
\text { Carageenan }\end{array}$ & $\begin{array}{c}\text { After } \\
\text { Carageenan }\end{array}$ & $\begin{array}{c}1^{\text {st }} \\
\mathrm{Hr}\end{array}$ & $\begin{array}{c}2^{\text {nd }} \\
\mathrm{Hr}\end{array}$ & $\begin{array}{c}3^{\text {rd }} \\
\mathrm{Hr}\end{array}$ & $\begin{array}{c}4^{\text {th }} \\
\mathrm{Hr}\end{array}$ \\
\hline $\begin{array}{c}\text { Negative } \\
\text { Control }\end{array}$ & 0.66 & 0.81 & 0.90 & 0.91 & 0.92 & 0.94 \\
\hline $\begin{array}{c}\text { Positive } \\
\text { Control }\end{array}$ & 0.63 & 0.78 & 0.84 & 0.82 & 0.80 & 0.75 \\
\hline $0.25 \%$ & 0.64 & 0.80 & 0.87 & 0.87 & 0.88 & 0.89 \\
\hline $0.50 \%$ & 0.69 & 0.84 & 0.90 & 0.89 & 0.88 & 0.88 \\
\hline $0.75 \%$ & 0.63 & 0.77 & 0.84 & 0.83 & 0.82 & 0.80 \\
\hline $1 \%$ & 0.71 & 0.86 & 0.90 & 0.87 & 0.84 & 0.80 \\
\hline
\end{tabular}

Table VII displays the average reading of the rat foot edema obtained from the pletysmometer. The readings from the pletysmometer indicate the increase in the edema during the first two hours. The decrease in foot edema is seen in the third and the fourth hour for the positive control, $0.75 \%$ gel, and $1 \%$ gel.

Table VIII displays the obtained mean difference from the average pletysmometer readings of the foot edema with reference to the different concentrations. Statistical treatment on the data shows that there is significant difference between the negative control and the different gel preparations which indicates that the latter possess antiinflammatory activity.
TABLE VIII: THE COMPARISON OF MEAN REDUCTION OF NEGATIVE CONTROL, POSITIVE CONTROL, $0.25 \%, 0.50 \%, 0.75 \%$, AND $1 \%$ ON THE $4^{\text {TH }}$ HOUR

\begin{tabular}{|c|c|c|c|c|}
\hline (I) & $(\mathrm{J})$ & Mean Difference (I-J) & p-value & Conclusion \\
& & & & \\
\hline \multirow{5}{*}{ Negative } & $0.25 \%$ & $-4.42267^{*}$ & .012 & Significant \\
\cline { 2 - 5 } & $0.50 \%$ & $-11.36867^{*}$ & .000 & Significant \\
\cline { 2 - 5 } & $0.75 \%$ & $-12.31267^{*}$ & .000 & Significant \\
\cline { 2 - 5 } & $1.00 \%$ & $-22.27517^{*}$ & .000 & Significant \\
\hline \multirow{5}{*}{ Positive } & $0.25 \%$ & $15.34350^{*}$ & .000 & Significant \\
\cline { 2 - 5 } & $0.50 \%$ & $8.39750^{*}$ & .000 & Significant \\
\cline { 2 - 5 } & $0.75 \%$ & $7.45350^{*}$ & .000 & Significant \\
\cline { 2 - 5 } & $1.00 \%$ & -2.50900 & .330 & Insignificant \\
\hline \multirow{3}{*}{$0.25 \%$} & $0.50 \%$ & $-6.94600^{*}$ & .000 & Significant \\
\cline { 2 - 5 } & $0.75 \%$ & $-7.89000^{*}$ & .000 & Significant \\
\cline { 2 - 5 } & $1.00 \%$ & $-17.85250^{*}$ & .000 & Significant \\
\hline \multirow{2}{*}{$0.50 \%$} & $0.75 \%$ & -.94400 & .969 & Insignificant \\
\cline { 2 - 5 } & $1.00 \%$ & $-10.90650^{*}$ & .000 & Significant \\
\hline $0.75 \%$ & $1.00 \%$ & $-9.96250^{*}$ & .000 & Significant \\
\hline
\end{tabular}

The mean difference between the positive control and the gel preparations, except for the $1 \%$ gel, shows significant differences. This significant differences shows that the $0.25 \%, 0.50 \%$, and $0.75 \%$ gel preparations are not comparable with the positive control. The insignificant difference of the mean difference of the positive and the $1 \%$ gel preparation states that the latter possess similar or comparable anti-inflammatory activity with $1 \%$ diclofenac gel.

Between the different gel concentrations, the $0.50 \%$ and $0.75 \%$ mean differences have insignificant difference. It indicates that the two said concentrations.

The results of the statistical treatment show that the $J$. sambac extract gel preparations possess anti-inflammatory activity. The $1 \%$ gel has comparable activity to $1 \%$ Diclofenac emugel.

\section{REFERENCES}

[1] J. L. Kee et al., Pharmacology; A Nursing Process Approach, 5th ed. Singapore: Elvesier, 2006.

[2] E. A. Quixumbing, Medicinal plants of the Philippines, Philippines: Katha, 1978.

[3] J. Bangale et al., "Preliminary studies on anti-inflammatory and analgesic activities of $J$. sambac (L.) aiton in experimental animal models," American Journal of PharmTech Research, vol. 2, pp. 22493387, 2012

[4] B. Sudhir, G. D. Gupta, and V. K. Sharma, "Topical gel: A novel approach for drug delivery," Journal of Chemical, Biological and Physical Sciences, vol. 2, pp. 856-867, Feb. 2012.

[5] U. D. Shivhare, V. B. Jain, K. P. Mathur, A. A. Bhusari, and S. Roy, "Formulation development and evaluation of diclofenac sodium gel using water soluble polyacrylamide polymer," Digest Journal of Nanomaterials and Biostructures, vol. 4, pp. 285-290, Aug. 2009.

[6] P. M. Crucis, Manufacturing Pharmacy Manual, Manila: Adamson University, 2011.

[7] L. Allen et al., Remington: The Science and Practice of Pharmacy, $22^{\text {nd }}$ ed., Pharmaceutical Press, 2012.

[8] Operation Manual for NDJ Series and SNB Series Digital Viscometer, SNB Series Product Standard: Q/SGKW6

[9] A. A. Sheikh and K. R. Biyani, "Formulation and evaluation of topical gel of diclofenac sodium," Journal of Pharmacy Research, vol. 4, pp. 2514-2516, Aug. 2011

[10] B. Guevarra et al., A Guidebook to Plant Screening: Phytochemical and Biological, revised ed., Manila: University of Santo Tomas Publishing House, 2012.

[11] Federal Hazardous Substance Act, 15 U.S.C., pp. 1261-1278, 2011.

[12] P. A. Kulkarni, S. Kewatkar, M. D. Lande, M. A. Phanse, and P. D. Chaudhari, "Topical anti-inflammatory activity of herbal gel formulation," Der Pharma Chemica, pp. 338-342, 2010. 
[13] O. Braun-Falco and H. C. Korting, "Normal pH Value of Human Skin," Der Hautarzt, vol. 3, pp. 126-129, 1986

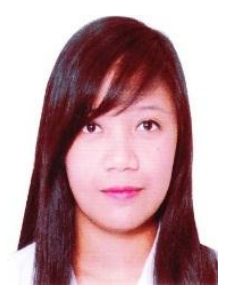

Yvonne Mae C. Belango is a holder of a baccalaureate degree in Pharmacy obtained from Adamson University, Ermita, Manila, Philippines. She graduated last March 2013.

She is currently preparing to take the licensure exams for pharmacists in the Philippines.

She is a member of the Junior Federation of Philippine Pharmacist Association - Rho Chapter.

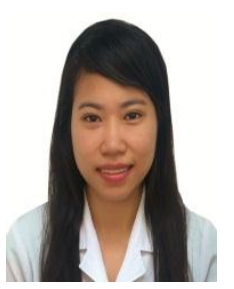

Arlene F. Cruz is a holder of a baccalaureate degree in pharmacy obtained from Adamson University, Ermita, Manila, Philippines. She graduated last March 2013.

She is currently preparing to take the licensure exams for pharmacists in the Philippines.

She is a member of the Junior Federation of Philippine Pharmacist Association - Rho Chapter.

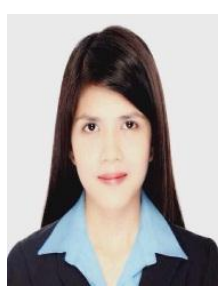

Chad Rilyn L. Rotairo is a holder of a baccalaureate degree in pharmacy obtained from Adamson University, Ermita, Manila, Philippines. She graduated last March 2013

She is currently preparing to take the licensure exams for pharmacists in the Philippines.

She is a member of the Junior Federation of Philippine Pharmacist Association - Rho Chapter.
Rhoda B. Miguel is currently a B.S. degree in pharmacy student in Adamson University, Ermita, Manila, Philippines.

She is presently fulfilling requirements to finish her baccalaureate degree.

She is a member of the Junior Federation of Philippine Pharmacist Association - Rho Chapter.

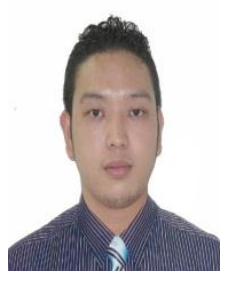

Riel Anthony T. Oli is a registered pharmacist in the Philippines. He finished his baccalaureate and master's degrees in pharmacy in Saint Louis University, Baguio City, Philippines in October 2008 and March 2013, respectively. He is currently a doctor of philosophy in pharmacy in the University of Santo Tomas, Espana, Manila, Philippines

$\mathrm{He}$ is currently a faculty member of the College of Pharmacy, Adamson University, Ermita, Manila, Philippines. He also worked as a faculty member in Saint Louis University and Pines City Colleges, and a pharmacist in Manson Drug Corporation. He is currently working for researchers associated with Biorisk Management, Jasminum sambac and pharmacoenvironmental studies.

Mr. Oli is an active member of the Philippine Pharmacist Association, Philippine Association of Colleges of Pharmacy, Young Pharmacists Group, Philippines, and Philippine Advanced Biorisk Officers. He is an Outcome-Based Education (OBE) Core Group member of Adamson University, a member of the Institutional Biorisk Committee and ISO Internal Audit Committee. 